\title{
BMJ Open Hospitalisation for heart failure and mortality associated with dipeptidyl peptidase 4 (DPP-4) inhibitor use in an unselected population of subjects with type 2 diabetes: a nested case-control study
}

\author{
Carlo B Giorda, ${ }^{1}$ Roberta Picariello, ${ }^{2}$ Barbara Tartaglino, ${ }^{3}$ Lisa Marafetti, ${ }^{1}$ \\ Fabiana Di Noi, ${ }^{1}$ Annalisa Alessiato, ${ }^{1}$ Giuseppe Costa, ${ }^{2,4}$ Roberto Gnavi ${ }^{2}$
}

To cite: Giorda CB, Picariello R, Tartaglino B, et al. Hospitalisation for heart failure and mortality associated with dipeptidyl peptidase 4 (DPP-4) inhibitor use in an unselected population of subjects with type 2 diabetes: a nested case-control study. BMJ Open 2015:5:e007959. doi:10.1136/bmjopen-2015007959

- Prepublication history for this paper is available online. To view these files please visit the journal online (http://dx.doi.org/10.1136/ bmjopen-2015-007959).

Received 16 February 2015 Revised 24 April 2015 Accepted 27 April 2015

\section{CrossMark}

\footnotetext{
${ }^{1}$ Metabolism and Diabetes Unit, ASL T05, Regione Piemonte, Chieri, Italy ${ }^{2}$ Epidemiology Unit, ASL T03, Regione Piemonte, Grugliasco, Italy

${ }^{3}$ Chaira Medica Association, Chieri, Italy

${ }^{4}$ Department of Clinical and Biological Sciences,

University of Torino, Torino, Italy
}

Correspondence to Dr Carlo Giorda;

giordaca@tin.it

\section{ABSTRACT}

Objective: The SAVOR TIMI-53 study reported a significant increase in the risk of hospitalisation for heart failure (HF) in patients treated with a DPP-4 inhibitor (DPP-4i) in comparison with placebo. A recent casecontrol study in part confirmed this risk signal. Our aim was to compare the occurrence of $\mathrm{HF}$ in relation to DPP$4 i$ use versus any antidiabetic treatment.

Design: Population-based matched case-control study conducted using administrative data.

Setting: The Italian Region of Piedmont (4.4 million inhabitants).

Participants: From a database of 282000 patients treated with antidiabetic drugs, we identified 14613 hospitalisations for HF, 7212 incident cases, and 1727 hospital re-admissions between 2008 and 2012; each case was matched for gender, age and antidiabetic therapy with 10 controls; cases and controls were compared for exposure to DPP-4i.

Outcome measures: ORs and $95 \% \mathrm{Cls}$ were calculated by fitting a conditional logistic model. All analyses were adjusted for available risk factors for $\mathrm{HF}$. Results: We found no increased risk of hospitalisation for HF associated with the use of DPP-4i (OR for admission for HF 1.00 (0.94 to 1.07), incident HF1.01 (0.92 to 1.11), recurrent HF 1.02 (0.84 to 1.22)). Allcause mortality was $6 \%$ lower in DPP-4i users $(p<0.001)$, whereas insulin users showed an excess of risk for any type of hospital admission (19\%) and death $(20 \%)(p<0.001)$.

Conclusions: Our findings suggest that, in an unselected population of diabetic patients, the use of DPP-4i is not associated with an increased risk of HF. The favourable impact on all-cause mortality should be viewed with caution and also other explanations investigated.

\section{INTRODUCTION}

DPP-4 inhibitors (DPP-4i), or gliptins, are oral agents that delay the catabolism of
Strengths and limitations of this study

- This study suggests that, in an unselected population of diabetic patients, the use of DPP-4i is not associated with an increased risk of HF.

- The study population was representative of the real type 2 diabetes population seen in Europe, without any selection based on insurance claims or age cut-off, which distinguishes it from other published studies.

- Hospitalisation for HF was evaluated as admission, incidence or recurrence, and all five drugs currently available on the market were included.

- The main limitation is that weak associations between DPP-4i use and heart failure cannot be ruled out; but if they do exist, they are not so large but if they were to exist, they would be relatively small.

- While looking forward to the results of ongoing trials, practitioners can be reassured that the unexpected association reported in the SAVOR TIMI study has not been confirmed in the real world.

native GLP-1 by inhibiting the endogenous enzyme dipeptidyl peptidase 4 (DPP-4), thus extending the life of native GLP-1. They have attracted growing interest as first line therapies for type 2 diabetes largely because they are effective in controlling HbAlc while reducing the risk of hypoglycaemia and weight gain. Data from trials with glycaemic endpoints suggest that they also exert a protective effect on cardiovascular risk. ${ }^{1}$ In the first published trial with cardiovascular endpoints, ${ }^{2}$ saxagliptins neither increase, nor reduce, the risk of a composite of nonfatal myocardial infarction (MI) with nonfatal stroke or cardiovascular death, thereby 
meeting the primary safety objective. However, as compared with placebo, saxagliptin was unexpectedly associated with a $27 \%$ excess risk of hospitalisation for heart failure (HF) (overall HR 1.27 (95\% CI 1.07 to 1.51)). Detailed sub-analyses ${ }^{3}{ }^{4}$ revealed that the absolute difference between groups was mainly seen during the first 6 months of therapy and that there was no increased risk of death due to heart failure. No clinically relevant factors predictive of increased relative risk with saxagliptin treatment could be definitively identified. ${ }^{5}$ A subsequent meta-analysis of all registrative trials with DPP-4i showed an association between the use of this class of drugs and increased risk of HF, which disappears when excluding cardiovascular outcome trials. ${ }^{6}$

Conflicting evidence for an association between sitagliptin use and hospitalisation for heart failure in some specific conditions comes from recent observational studies. Wang et al found an increased risk of hospitalisation for HF in with sitagliptin use in Taiwanese insured individuals whereas Chen et $a l^{8}$ reported no increased risk in patients with history of chronic kidney disease and myocardial infarction. Weir $e t a t^{p}$ in particular reported that in a case-control study, based on an administrative database of US middle-aged adults with type 2 diabetes, treatment with sitagliptin was associated with an increased probability of hospitalisation for heart failure only among patients with pre-existing heart failure.

This safety issue is relevant for diabetes care because the rates of heart failure and hospitalisation are higher in patients with type 2 diabetes than in the non-diabetic population, regardless of treatment. ${ }^{10-12}$ Further complicating the question is that several drugs commonly used in the treatment of type 2 diabetes have been suspected to increase the risk of $\mathrm{HF}^{13}$

In light of the concerns over a possible HF risk associated with DPP-4i, we thought it useful to perform a matched case-control study to explore whether the same increased risk as seen in the SAVOR-TIMI study could be detectable in the real world and in an unselected population. To the best of our knowledge, no such analysis has been performed on data from European administrative databases which, by virtue of the universalistic care of European national health systems, encompass the whole population and include all types of available DPP-4i.

\section{METHODS}

\section{Study design and participants}

We conducted a population-based nested case-control study using regional administrative data from Piedmont (population about 4.4 million) Italy. The population is covered by an automated system of databases containing the records of all drugs dispensed from all regional pharmacies and hospital discharges reimbursed by the Italian National Health System. These archives can be linked together by a unique anonymous identifier that is encrypted to protect the patient's privacy. Because this automated system is anonymous, ethical committee approval and informed consent for this study were not required.

\section{Procedures}

We extracted information from the regional drug prescription database for individuals aged 56 years or older who were dispensed at least one dose of any drug to treat diabetes between 1 January 2009 and 31 December 2013 (DPP-4i were not available in Italy before 2008). Only Piedmont residents were included. To minimise the chance of inclusion of patients with type 1 diabetes, we linked the database to the regional hospital discharge database, which contains the records of all hospital admissions between 1995 and 2013. Excluded were individuals with an International Classification of Diseases, 9th Edition, Clinical Modification (ICD-9-CM) code for type 1 diabetes mellitus (250.x1 or 250.x3). Furthermore, as glitazones (TZD) increase the risk of heart failure, all patients who had received a prescription for TZD during the study period were excluded.

\section{Selection of cases}

We used four different definitions for cases. First, we identified all patients who had at least one discharge for heart failure, defined as ICD-9-CM codes 402.01, 402.11, 402.91, $425.4,425.5,425.9,428$ or 518.4 as the primary discharge diagnosis at any time after the first exposure to antidiabetic drugs (ie, date of dispensation). For patients with more than one discharge for heart failure, we only included the first episode (ie, the hospital admission closest to 1 January 2009). Second, we identified 'incident' cases of heart failure, defined as patients discharged with a diagnosis of heart failure (defined as above) during the study period, without a previous hospitalisation for heart failure in the discharge diagnosis (either main or secondary) during the previous 60 months. Third, similarly to the study by Weir $e t a l,{ }^{9}$ we followed up incident cases (defined as above) to identify 'first re-hospitalisations' of those patients who had been admitted to hospital for a diagnosis of heart failure. Finally, we considered as cases all deaths (of any cause) that occurred in the population during the study period. Also included were Piedmont residents discharged from any hospital located outside Piedmont, because information on exposure to dispensed drugs is available for all patients residing in the region. Similarly, we included the deaths of Piedmont residents wherever they occurred in Italy.

\section{Selection of controls}

To identify controls, we randomly selected 10 controls from the same population source for each case, matched for year of birth (within a 5-year age band), sex and year of first exposure to antidiabetic drugs. Controls were selected one subject at a time with replacement. The process was repeated for each outcome. Matching was carried out by the study statistician (RP) with the use of an automated computer program. 
Exposure to DPP-4 inhibitors

We used the regional drug database to identify cases and controls who had been prescribed DPP-4i at any time in the 6 months before the hospital admission date. We used the hospital admission date of cases to calculate the exposure windows for controls. DPP-4i were selected according to the Anatomical Therapeutic Chemical (ATC) Classification System; ATC codes A10BH01+A10BD07 (Sitagliptin), A10BH02+A10BD08 (Vildagliptin), A10BH03 +A10BD10 (Saxagliptin) and A10BH05+A10BD11 (Linagliptin) were considered.

\section{Ascertainment of potential confounders}

We defined potential confounders from the regional hospital discharge database as hospital admissions that occurred up to 5 years before the index date for ischaemic heart diseases (ICD-9-CM 410-414). Likewise, we also included individuals who had been treated with glimepiride (ATC code A10BB12) or glibenclamide (ATC code $\mathrm{A} 10 \mathrm{BB} 01)$ in the 6 months prior to the date of hospital admission. Treatment with insulin (ATC A10A) in the 6 months prior to the date of hospital admission was regarded as proxy of severity of disease.

\section{Statistical analysis}

We calculated the proportions of categorical variables in cases and controls, and assessed the differences in baseline characteristics with the $\chi^{2}$ test. We estimated the risk of the four different outcomes associated with dispensation of any DPP-4i by fitting conditional logistic regression models, expressed as ORs, and corresponding 95\% CIs. We adjusted the statistical models for the aforementioned confounders. Confounders included in the final models were past history of ischaemic heart disease, insulin use and glimepiride or glibenclamide (considered together) use. In the sensitivity analyses, we assessed the use of DPP-4i at any time before hospital admission or death. All analyses were performed using the SAS PHREG procedure V.9.2.

\section{RESULTS}

During the study period, 14613 cases of hospital admission for heart failure, 7212 incident cases of heart failure, 1727 cases of re-admission and 38248 deaths occurred within this population of patients with type 2 diabetes. Compared with controls, the use, as well as the type, of DPP-4i did not differ between cases and controls for heart failure outcomes (between 1.8 and $2.0 \%$ of both cases and controls were on gliptins), whereas the use of insulin, but not of glibenclamide, was more frequent among the cases. There was a higher prevalence of ischaemic heart disease among the cases. When mortality was considered as an outcome, exposure to DPP-4i was lower among the cases than the controls $(0.8 \%$ vs $1.8 \%$ ) (table 1).

After adjustment for available confounders, the use of gliptins up to 6 months before any of the outcomes considered was not associated with the risk of hospitalisation for heart failure (OR 1.00, 95\% CI 0.94 to 1.07; $\mathrm{p}=0.9832$ ), incident heart failure (OR $1.01,95 \%$ CI 0.92 to $1.11 ; \mathrm{p}=0.7808$ ), hospital re-admission for heart failure (OR $1.02,95 \%$ CI 0.84 to $1.22 ; p=0.8745$ ), or death of any cause (OR $0.94,95 \%$ CI 0.90 to $0.98 ; \mathrm{p}=0.0021$ ). A history of ischaemic heart disease or insulin use was associated with an increased risk of all the outcomes considered, except for hospital re-admission for heart failure (table 2). In the sensitivity analysis, in which the time window was extended to include DPP-4i use at any time before the outcomes under study, the ORs were unchanged for all outcomes: hospital admission (OR $0.99,95 \%$ CI 0.94 to $1.05 ; \mathrm{p}=0.8048)$, incident heart failure (OR 1.01, 95\% CI 0.93 to 1.09; $\mathrm{p}=0.8775$ ), hospital re-admission ( $\mathrm{OR} 0.97,95 \%$ CI 0.85 to 1.16 ; $\mathrm{p}=0.9558$ ), or death (OR $0.94,95 \%$ CI 0.91 to $0.98 ; \mathrm{p}=0.0018$ ).

\section{DISCUSSION}

The question of whether or not therapy with DPP-4i may increase the risk of heart failure has raised concern over the safety of these drugs among practitioners. ${ }^{4}$ The key message of our analysis is that, in a large unselected population of treated individuals with type 2 diabetes, no association was found, regardless of causality and as borne out by the neutral OR independent of the subgroup considered (Any admission, Incident or Re-admission for heart failure).

Our findings are in line with a very recent paper by $\mathrm{Yu}$ et $a l,{ }^{14}$ who reported no association between the use of these incretin-based therapies, studied as a whole DPPi and GLP1 receptor agonists, and incident heart failure in patients with type 2 diabetes. The same concordance exists with the general message from animal studies and pathophysiological investigations, which found no detrimental effect of DPP-4i on cardiac function. ${ }^{15} 16$ However, it is a puzzling link because two other recent physiopathological studies in patients produced unanticipated findings that treatment with DPP-4i could exacerbate heart failure. ${ }^{17}{ }^{18}$ Moreover, since no plausible explanation for the SAVOR TIMI 53 finding has been forthcoming, it is difficult to speculate on the reasons for the differences between their findings and our findings in the drug-associated risk of heart failure.

Weir et a ${ }^{\ominus}$ found a significantly increased risk of hospitalisation for heart failure associated with the use of sitagliptin among adults with type 2 diabetes, but only in patients with pre existing heart failure, with a relevant $84 \%$ excess of risk. One possible, though still speculative, explanation for this discrepancy could be an indication bias contending that, before the SAVOR TIMI results were published, DPP-4i use was well regarded and considered particularly safe in patients with left ventricular dysfunction or renal insufficiency. On closer analysis, the two study populations differ in average age (78 vs 54 years) and background antidiabetes therapies. An additional difference lies in the choice of cases, with the 
Table 1 Baseline characteristics

\begin{tabular}{|c|c|c|c|c|c|c|c|c|c|c|c|c|}
\hline & \multicolumn{3}{|c|}{ Any admission for HF } & \multicolumn{3}{|l|}{ Incident HF } & \multicolumn{3}{|c|}{ Re-admission for HF } & \multicolumn{3}{|c|}{ All-cause mortality } \\
\hline & $\begin{array}{l}\text { Cases } \\
(n=14613)\end{array}$ & $\begin{array}{l}\text { Controls } \\
(n=146130)\end{array}$ & p Value & $\begin{array}{l}\text { Cases } \\
(n=7212)\end{array}$ & $\begin{array}{l}\text { Controls } \\
(n=72120)\end{array}$ & p Value & $\begin{array}{l}\text { Cases } \\
(n=1727)\end{array}$ & $\begin{array}{l}\text { Controls } \\
(n=17 \text { 222) }\end{array}$ & p Value & $\begin{array}{l}\text { Cases } \\
(n=38248)\end{array}$ & $\begin{array}{l}\text { Controls } \\
(n=382313)\end{array}$ & p Value \\
\hline Age at recruitment, years & $78.0(8.3)$ & $77.9(8.4)$ & & $78.3(8.4)$ & $78.2(8.4)$ & & $77.9(8.4)$ & $77.9(8.5)$ & & $80.2(9.1)$ & $79.9(9.0)$ & \\
\hline Sex male & $7690(52.6)$ & $76900(52.6)$ & & $3577(49.6)$ & $35770(49.6)$ & & 914 (52.9) & $9102(52.9)$ & & $19215(50.2)$ & $191983(50.2)$ & \\
\hline DPP-4i use (6 months) & $256(1.8)$ & $2881(2.0)$ & 0.0672 & $135(1.9)$ & $1285(1.8)$ & 0.5820 & $37(2.1)$ & $338(2.0)$ & 0.6090 & $306(0.8)$ & $6717(1.8)$ & $<0.0001$ \\
\hline DPP-4i use (any) & $328(2.2)$ & $3636(2.5)$ & 0.0702 & $171(2.4)$ & $1657(2.3)$ & 0.6917 & $47(2.7)$ & $470(2.7)$ & 0.9853 & $477(1.3)$ & $8491(2.2)$ & $<0.0001$ \\
\hline \multicolumn{13}{|c|}{ Previous disorders or treatments } \\
\hline $\begin{array}{l}\text { Ischaemic heart disease } \\
\text { (in the past } 5 \text { years) }\end{array}$ & $3371(23.1)$ & $10237(7.0)$ & $<0.0001$ & $879(12.2)$ & $5492(7.6)$ & $<0.0001$ & $281(16.3)$ & $2361(13.7)$ & 0.0034 & 4270 (11.2) & $23938(6.3)$ & $<0.0001$ \\
\hline $\begin{array}{l}\text { Glimepiride or } \\
\text { glibenclamide (in the past } \\
6 \text { months) }\end{array}$ & $1531(10.5)$ & $16756(11.5)$ & 0.0003 & 916 (12.7) & 8144 (11.3) & 0.0003 & $172(10.0)$ & $1691(9.8)$ & 0.8516 & $3428(9.0)$ & 46327 (12.1) & $<0.0001$ \\
\hline $\begin{array}{l}\text { Insulin (in the past } \\
6 \text { months) }\end{array}$ & $5363(36.7)$ & $24108(16.5)$ & $<0.0001$ & 2177 (30.2) & 12042 (16.7) & $<0.0001$ & 730 (42.3) & 4459 (25.9) & $<0.0001$ & $14159(37.0)$ & 64477 (16.9) & $<0.0001$ \\
\hline
\end{tabular}

Table 2 Matched ORs of different outcomes associated with exposure to DPP-4i in the 6 months before index date

\begin{tabular}{|c|c|c|c|c|c|c|c|c|}
\hline & \multicolumn{2}{|c|}{ Any admission for $\mathrm{HF}$} & \multicolumn{2}{|l|}{ Incident HF } & \multicolumn{2}{|c|}{ Re-admission for HF } & \multicolumn{2}{|l|}{ All-cause mortality } \\
\hline & $\begin{array}{l}\text { Unadjusted OR } \\
(95 \% \text { CI); p value }\end{array}$ & $\begin{array}{l}\text { Adjusted OR } \\
(95 \% \mathrm{Cl}) ; \mathrm{p} \text { value }\end{array}$ & $\begin{array}{l}\text { Unadjusted OR } \\
(95 \% \mathrm{Cl}) ; p \text { value }\end{array}$ & $\begin{array}{l}\text { Adjusted OR } \\
(95 \% \mathrm{Cl}) ; p \text { value }\end{array}$ & $\begin{array}{l}\text { Unadjusted OR } \\
(95 \% \text { CI); p value }\end{array}$ & $\begin{array}{l}\text { Adjusted OR } \\
(95 \% \mathrm{Cl}) ; p \text { value }\end{array}$ & $\begin{array}{l}\text { Unadjusted OR } \\
(95 \% \mathrm{Cl}) ; \mathrm{p} \text { value }\end{array}$ & $\begin{array}{l}\text { Adjusted OR } \\
(95 \% \mathrm{Cl}) ; p \text { value }\end{array}$ \\
\hline DPP-4i use & $\begin{array}{l}0.99(0.92 \text { to } 1.05) \\
p=0.6383\end{array}$ & $\begin{array}{l}1.00(0.94 \text { to } 1.07) \\
p=0.9832\end{array}$ & $\begin{array}{l}1.01(0.92 \text { to } 1.11) \\
p=0.8867\end{array}$ & $\begin{array}{l}1.01(0.92 \text { to } 1.11) \\
p=0.7808\end{array}$ & $\begin{array}{l}1.01(0.84 \text { to } 1.22) \\
p=0.8944\end{array}$ & $\begin{array}{l}1.02(0.84 \text { to } 1.22) ; \\
p=0.8745\end{array}$ & $\begin{array}{l}0.93(0.89 \text { to } 0.97) \\
p=0.0005\end{array}$ & $\begin{array}{l}0.94(0.90 \text { to } 0.98) \\
p=0.0021\end{array}$ \\
\hline \multicolumn{9}{|c|}{ 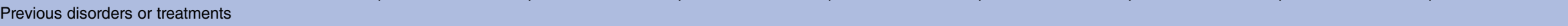 } \\
\hline Ischaemic heart disease (in the past 5 years) & $\begin{array}{l}1.36(1.31 \text { to } 1.40) \\
p=<0.0001\end{array}$ & $\begin{array}{l}1.34(1.29 \text { to } 1.38) \\
p=<0.0001\end{array}$ & $\begin{array}{l}1.09(1.04 \text { to } 1.14) ; \\
p=0.0003\end{array}$ & $\begin{array}{l}1.08(1.03 \text { to } 1.13) ; \\
p=0.0014\end{array}$ & $\begin{array}{l}1.03(0.96 \text { to } 1.11) \\
p=0.4455\end{array}$ & $\begin{array}{l}1.02(0.95 \text { to } 1.10) \\
p=0.6067\end{array}$ & $\begin{array}{l}1.11(1.09 \text { to } 1.14) \\
p=<0.0001\end{array}$ & $\begin{array}{l}1.09(1.07 \text { to } 1.12) ; \\
p=<0.0001\end{array}$ \\
\hline $\begin{array}{l}\text { Glimepiride or glibenclamide (in the past } \\
6 \text { months) }\end{array}$ & $\begin{array}{l}0.99 \text { (0.96 to } 1.02) \\
p=0.3555\end{array}$ & $\begin{array}{l}1.01(0.98 \text { to } 1.04) \\
p=0.4844\end{array}$ & $\begin{array}{l}1.02(0.98 \text { to } 1.06) \\
p=0.3520\end{array}$ & $\begin{array}{l}1.03 \text { (0.99 to } 1.08) ; \\
p=0.0998\end{array}$ & $\begin{array}{l}1.00(0.92 \text { to } 1.09) \\
p=0.9614\end{array}$ & $\begin{array}{l}1.02(0.93 \text { to } 1.11) \\
p=0.6751\end{array}$ & $\begin{array}{l}0.96(0.95 \text { to } 0.98) \\
p=<0.0001\end{array}$ & $\begin{array}{l}0.98(0.97 \text { to } 1.00) \\
p=0.0540\end{array}$ \\
\hline Insulin (in the past 6 months) & $\begin{array}{l}1.21(1.18 \text { to } 1.24) ; \\
p=<0.0001\end{array}$ & $\begin{array}{l}1.19(1.17 \text { to } 1.22) \\
p=<0.0001\end{array}$ & $\begin{array}{l}1.13(1.10 \text { to } 1.17) ; \\
p=<0.0001\end{array}$ & $\begin{array}{l}1.13(1.10 \text { to } 1.17) ; \\
p=<0.0001\end{array}$ & $\begin{array}{l}1.12(1.06 \text { to } 1.19) ; \\
p=0.0001\end{array}$ & $\begin{array}{l}1.12(1.06 \text { to } 1.19) ; \\
p=0.0002\end{array}$ & $\begin{array}{l}1.20(1.19 \text { to } 1.22) ; \\
p=<0.0001\end{array}$ & $\begin{array}{l}1.20(1.18 \text { to } 1.21) ; \\
p=<0.0001\end{array}$ \\
\hline
\end{tabular}

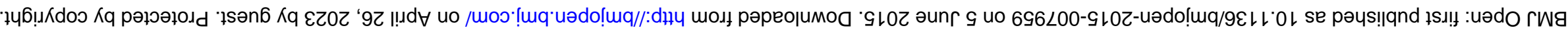


American population appearing as a rather select population of young insured individuals.

The favourable impact of DPP-4i use on all-cause mortality is welcome but still warrants caution. It could confirm recent observational data that suggested a reduction of mortality in the Danish diabetic population on incretins. ${ }^{19}$ It should also be remembered, however, that DPP-4i use can represent a marker of better specialty care. ${ }^{20}$

Our analysis, by contrast, beyond the expected role of previous ischaemic heart disease as a factor underlying impaired myocardial performance, revealed an important link between insulin use and risk of heart failure for first as well as for recurrent hospitalisation. This finding is neither new nor surprising. In the last several years, numerous observational studies have found insulin to be a marker of poor cardiovascular outcomes, including heart failure, ${ }^{21}$ raising the question of the possible pathogenetic role of hypoglycaemic events. Why the outcomes of insulin use in observational studies clash with the findings from randomised controlled trials such as the UKPDS ${ }^{22}$ and ORIGIN,${ }^{23}$ and seem to dismiss the role insulin can play in preventing complications, is perplexing. For instance, the DAI study, the largest cohort study on complications of diabetes in Italy, found a correlation between insulin therapy and the occurrence of coronary disease and stroke. ${ }^{24}$ Similar conclusions were reported for heart failure. ${ }^{25}$ A simple explanation would be that there is a typical indication bias. A more complex rationalisation would point to the problem of clinical inertia: insulin in the real world is given late, after chronic exposure to high glucose levels, thus marking subjects with poor irreversible legacy. In other words, the outcome after insulin therapy in observational studies may reflect the fact that it is initiated too late rather than its appropriate use.

Our study has several strengths. It was conducted using data retrieved from a population-based database representative of the real type 2 diabetes population seen in Europe, without any selection based on insurance claims, and, in particular, with no age cut-off, two factors that distinguish it from other published studies using administrative data. Our approach thus eliminated recall bias and minimised selection bias. All five drugs currently available on the market were included. Furthermore, as DPP-4i are dispensed and reimbursed only by prescription, we are confident to have included all dispensations.

Our study also has potential limitations, however. Though the sample size is rather large, this should not be a concern: with the use of a one-sided test at the $\alpha=5 \%$ level, the smallest risk, greater than one, that could be detected with $80 \%$ power is OR=1.16 for hospital admissions, 1.24 for incident heart failure and 1.49 for hospital re-admissions. We are aware that a weaker association between DPP-4i use and heart failure cannot be ruled out; but if it does exist, it would be relatively small. Another weakness is the missing data on metabolic control and other clinical variables such as NT-pro BNP levels, hypertension, heart valve defects and renal failure, all of which could have impacted on hospitalisation rates for heart failure. Nonetheless, there is no reason why this could have favoured the control group and thus masked the association. As a proxy of diabetes severity, we adjusted for cardiovascular disease and level of therapy. We did not consider medication dose or adherence to therapy and, given the low prevalence of exposed individuals, we were unable to factor in the effect of the different compounds separately. In addition, the use of a database of dispensed drugs rather than usage data might have overestimated DPP-4i use; however, it is unlikely that this would have affected cases and controls differently. Finally, only severe cases of heart failure hospitalisation were considered, leaving open the question of whether or not milder episodes of cardiac insufficiency, not resulting in hospital admission, could have been increased in DPP-4i users.

Ongoing trials, including the Sitagliptin Cardiovascular Outcome Study ${ }^{26}$ and the Functional Impact of GLP-1 for Heart Failure Treatment, ${ }^{27}$ may help to clarify the conflicting findings. Meanwhile, practitioners can be reassured that the unexpected association reported in the SAVOR TIMI study has not been confirmed in the real world.

Contributors CBG: literature search, study design, data collection, data interpretation, writing; RP: data collection, data analysis; $B T, L M$ and $A A$ : literature search, writing assistance; GC: data interpretation, writing; RG: literature search, study design, data collection, data interpretation, writing. $\mathrm{CBG}, \mathrm{RP}, \mathrm{GC}$ and RG had access to the raw data. The corresponding author had full access to all the data in the study and the final responsibility for the decision to submit for publication. All authors approved the final version.

Funding This study was in part supported by an AMD (Italian Diabetologists Association) fellowship (AA) and Chaira Medica Association (non-profit organisation for the study of endocrine and metabolic disorders), Chieri, Italy, where BT is employee of the Association.

Competing interests None declared.

Provenance and peer review Not commissioned; externally peer reviewed.

Data sharing statement Technical appendix, statistical code and dataset were not made available in the Dryad repository. However, these data can be made available by request to the corresponding author.

Open Access This is an Open Access article distributed in accordance with the Creative Commons Attribution Non Commercial (CC BY-NC 4.0) license, which permits others to distribute, remix, adapt, build upon this work noncommercially, and license their derivative works on different terms, provided the original work is properly cited and the use is non-commercial. See: http:// creativecommons.org/licenses/by-nc/4.0/

\section{REFERENCES}

1. Monami M, Dicembrini I, Nardini C, et al. Effects of glucagon-like peptide-1 receptor agonists on cardiovascular risk: a meta-analysis of randomized clinical trials. Diabetes Obes Metab 2014;16:38-47.

2. Scirica BM, Bhatt DL, Braunwald E, et al, AVOR-TIMI 53 Steering Committee and Investigators. Saxagliptin and cardiovascular outcomes in patients with type 2 diabetes mellitus. $N$ Engl J Med 2013;369:1317-26.

3. Scirica BM, Braunwald E, Raz I, et al, for the SAVOR-TIMI 53 Steering Committee and Investigators. Heart failure, saxagliptin and diabetes mellitus: observations from the SAVOR-TIMI 53 randomized trial. Circulation 2014;130:1579-88.

4. Fonarow GC. Diabetes medications and heart failure: recognizing the risk. Circulation 2014;130:1565-7.

5. Scirica BM, Raz I, Cavender MA, et al, on behalf of the SAVOR-TIMI 53 Steering Committee and Investigators. Outcomes of patients with 
type 2 diabetes and known congestive heart failure treated with saxagliptin: analyses of the SAVOR-TIMI 53 Study. Poster number 5082 presented at American Heart Association 2013, Dallas, Texas, USA, 17 November 2013.

6. Monami M, Dicembrini I, Mannucci E. Dipeptidyl peptidase-4 inhibitors and heart failure: a meta-analysis of randomized clinical trials. Nutr Metab Cardiovasc Dis 2014;24:689-97.

7. Wang KL, Liu CJ, Huang CM, et al. Sitagliptin and the risk of hospitalization for heart failure: a population-based study. Int $J$ Cardiol 2014;177:86-90.

8. Chen DY, Wang SH, Mao CT, et al. Sitagliptin and cardiovascular outcomes in diabetic patients with chronic kidney disease and acute myocardial infarction: A nationwide cohort study. Int J Cardiol 2015;181:200-6.

9. Weir DL, McAlister FA, Senthilselvan A, et al. Sitagliptin use in patients with diabetes and heart failure: a population-based retrospective cohort study. JACC Heart Fail 2014;2:573-82.

10. Kannel WB, Hjortland M, Castelli WP. Role of diabetes in congestive heart failure: the Framingham study. Am J Cardiol 1974;34:29-34.

11. Chae CU, Glynn TJ, Manson JE, et al. Diabetes predicts congestive heart failure risk in the elderly. Circulation 1998;98:721.

12. Bell DS. Heart failure: the frequent, forgotten, and often fatal complication of diabetes. Diabetes Care 2003;26:2433-41.

13. Eurich DT, McAlister FA, Blackburn DF, et al. Benefits and harms of antidiabetic agents in patients with diabetes and heart failure: systematic review. BMJ 2007;335:497.

14. $\mathrm{Yu} \mathrm{OH}$, Filion $\mathrm{KB}$, Azoulay L, et al. Incretin-based drugs and the risk of congestive heart failure. Diabetes Care 2015;38:277-84.

15. Ussher JR, Drucker DJ. Cardiovascular actions of incretin-based therapies. Circ Res 2014;114:1788-803.

16. Khan MA, Deaton C, Rutter MK, et al. Incretins as a novel therapeutic strategy in patients with diabetes and heart failure. Heart Fail Rev 2013;18:141-8.

17. http://www.escardio.org/congresses/hf2013/congress-to-you/Pages/ vildagliptin-shows-no-adverse-effect-ejection-fraction-diabeticpatients-with-heart-failure.aspx (accessed 18 Nov 2014).
18. Ayaori M, Iwakami $\mathrm{N}$, Uto-Kondo $\mathrm{H}$, et al. Dipeptidyl vasodilatation in type 2 diabetic patients. J Am Heart Assoc 2013;2:e003277.

19. Mogensen UM, Andersson C, Fosbol EL, et al. Cardiovascular safety of combination therapies with incretin-based drugs and metformin compared with a a combination of metformin and sulphonylurea in type 2 diabetes mellitus-a retrospective nationwide study. Diabetes Obes Metab 2014;16:1001-8.

20. Giorda C, Picariello R, Elisa Nada E, et al. The impact of adherence to screening guidelines and of diabetes clinics referral on morbidity and mortality in diabetes. PLOS ONE 2012;7:e33839.

21. Giorda CB. Could clinical inertia in part explain the unexpected association of insulin therapy with poorer cardiovascular outcomes in observational studies on diabetes? Diabetes Res Clin Pract 2011;92:e47-8

22. Holman RR, Paul SK, Bethel MA, et al. 10-year follow-up of intensive glucose control in type 2 diabetes. N Engl J Med 2008;359:1577-89.

23. Gerstein HC, Bosch J, Dagenais GR, et al, The ORIGIN Tria Investigators. Basal insulin and cardiovascular and other outcomes in dysglycemia. N Engl J Med 2012;367:319-28.

24. Giorda CB, Avogaro A, Maggini M, et al, for the Diabetes and Informatics Study Group. Incidence and risk factors for stroke in type 2 diabetic patients: the DAl study. Stroke 2007;38:1154-60.

25. Nichols GA, Hillier TA, Erbey JR, et al. Congestive heart failure in type 2 diabetes: prevalence, incidence, and risk factors. Diabetes Care 2001;24:1614-19.

26. Green JB, Bethel MA, Paul SK, et al. Rationale, design, and organization of a randomized, controlled Trial Evaluating Cardiovascular Outcomes with Sitagliptin (TECOS) in patients with type 2 diabetes and established cardiovascular disease. Am Heart $J$ 2013;166:983-9.

27. Margulies KB, Anstrom KJ, Hernandez AF, et al, Heart Failure Clinical Research Network. GLP-1 agonist therapy for advanced heart failure with reduced ejection fraction: design and rationale for the functional impact of GLP-1 for heart failure treatment study. Circ Heart Fail 2014;7:673-9. 